\title{
ASPEK-ASPEK KELISANAN DALAM PROSALIRIS PENGAKUAN PARIYEM KARYA LINUS SURYADI AG
}

\section{(ORAL ASPECTS IN LYRICAL PROSE OF PENGAKUAN PARIYEM BY LINUS SURYADI AG)}

\author{
Bagus Kurniawan \\ Universitas Sebelas Maret Surakarta \\ Jalan Ir. Sutami No. 36-A, Solo, Indonesia \\ Pos-el:singawardhana@yahoo.com
}

Diterima: 3 Juni 2014; Direvisi: 13 Oktober 2014; Disetujui: 24 Oktober 2014

\begin{abstract}
Abstrack
The development of modern printed traditional arts is highly influcing the development of Indonesia literatures. The production phase from a traditional to amechanical industry affects to both the number of the literature productions and its supporting community. Tthe development of moderent printed media is also considered to signal the and of the classic literature tradition as well as the birth of a modern literature tradition. Moreover, the invention of the printed machine production technique is also considered to end the oral tradition in Indonesia community as well as to start a new tradition, the script tradition.

The easily accusable literature trigger literature trigger literature activities to leave spirit as in the oral tradition, in cartain condition, it could be tolerated, however Indonesian community is not totally leave out the oral tradition in their literature activity .this paper describes the path of folklore existing in literarature traditions in Indonesia community by analyzing the lyrical prose of pengakuan perayem by linus suryadi Ag., it is found out that the exiting of verbal aspects shows that Indonesia people have not totally moved to script literature .this research applies two theories, namely are folklore theory by walter j.ong and hegemony theory by Gramsci, folklore the oral aspect in a text, while hegemony theory is used to expectcts in a text while hegemony theory is used to explain the oral aspects in a text, while hegemony theory is used to explain the oral aspects a Javanese perspective.
\end{abstract}

Keyword: oral tradion, folklore path, oral tradition, Indonesia literatures

\begin{abstract}
Abstrak
Berkembangnya seni tradisi cetak modern berpengaruh besar terhadap perkembangan sastra Indonesia. fase modernisasi produksi dari tradisional ke industri mekanis berpengaruh pada jumlah produksi karya sastra dan perilaku masyarakat pendukungnya. Berkembangnya seni cetak modern kemudian juga dianggap menandai berakhirnya tradisi sastra klasik sekaligus menandai kelahiran tradisi sastra modern. Tidak hanya itu, adanya teknik produksi mesin cetak juga dianggap mengakhiri tradisi kelisanan dalam masyarakat Indonesia dan mengawali tradisi baru, yaitu tradisi keberaksaraan.
\end{abstract}


Akses masyarakat yang dianggap mudah untuk menjangkau karya sastra dianggap memicu perilaku aktivitas sastra yang meninggalkan semangat kolektivitas seperti halnya dalam tradisi lisan. Dalam hal tertentu, pemahaman itu dapat dibenarkan. Akan tetapi, Teeuw dalam bukunya yang berjudul Indonesia antara Kelisanan dan Keberaksaraan (1994) mengatakan bahwa masyarakat Indonesia tidak sepenuhnya meninggalakn tradisi kelisanan dalam situsi keberaksaraan mereka. Dalam tulisan ini, diuraikan mengenai jejak kelisanan yang masih tetap lestari dalam tradisi keberaksaraan masyarakat Indonesia. Melalui kajian terhadap prosa liris Pengakuan Pariyem karya Linus Suryadi Ag dapat diketahui bahwa masyarakat Indonesia masih suntuk dalam tradisi lisan mereka, belum beralih pada tradisi keberaksaraan yang sepenuhnya.

Kata kunci: tradisi lisan, jejak kelisanan, tradisi keberaksaraan, sastra Indonesia.

\section{Pendahuluan}

Karya sastra Indonesia modern lahir berkat pengenalan para sastrawan (muda) Indonesia terhadap kesusatraan Barat, khususnya lewat sastra Belanda. Karya sastra Barat dapat dianggap sebagai karya sastra internasional. Akan tetapi, dengan masuknya unsur internasional yang universal itu bukan berarti unsur-unsur sastra daerah hilang sama sekali, melainkan sebagian konvensinya masih tetap diteruskan ( Pradopo, 2003:58; lihat juga pendapat Hutomo, 1991:2; dan Sweeney, 1980: 36-37). Dari pendapat itu dapat diartikan bahwa terdapat ketegangan antara tradisi sastra lama dengan sastra modern di Indonesia (Teeuw, 1991:8). Beberapa hal yang bersumber dari tradisi lama masih terus berlangsung dan ditransformasikan ke dalam era sastra modern. Setidaktidaknya, ada dua nilai dalam tradisi lama yang tetap lestari setelah munculnya kesusatraan Indonesia modern. Pertama, adanya unsur-unsur kedaerahan dan kelokalan dalam kesusastraan Indonesia modern tahun 1970-an. Pada masa itu, muncul lagi warna-warna lokal yang begitu kuat dalam kesusastraan Indonesia modern di dalam sejumlah karya sastra. Kedua, tetap lestarinya ciri tradisi lama yang berupa unsur kelisanan dalam karyakarya sastra modern.

Situasi kesastraan semacam itu juga bukan tanpa sebab. Bagaimanapun, tradisi lisan, kesusastraan rakyat yang berupa folklore, pantun, macapat, dan sebagainya merupakan tradisi lama yang begitu kuat hidup di masyarakat pada masa lampau. Pendapat di atas juga didukung oleh seorang ahli antropologi, James Dananjaya (1984:46; bandingkan pula dengan Sastrowardoyo dkk. (Peny), 1983:2) yang menyatakan bahwa masyarakat Indonesia memiliki potensi yang begitu besar dalam hal kesusastraan 
rakyat yang sama sekali belum dituliskan. Perlu diingat pula bahwa sastra lisan/tradisi lisan memiliki elemen pokok seperti yang dikemukakan oleh Finnegan (1977:17), yaitu sangat erat dengan proses transmisi. Dengan demikian, kelisanan bagi masyarakat Indonesia adalah bagian dari sebuah tradisi yang telah berakar dengan kuat dan memungkinkan hal itu terus ditransmisikan dari generasi ke generasi.

Tradisi lisan di masyarakat Melayu dapat ditelusuri melalui konsep pelipur lara. Masyarakat Melayu terbiasa mendengarkan sang pelipur lara setelah mereka lelah seharian bekerja di ladangladang mereka. Secara kolektif mereka mendengarkan syair-syair, pantun-pantun, hikayat yang berisi hiburan bagi mereka (lihat dalam Fang, 1991:3). Cerita-cerita semacam itu di masyarakat Melayu ditransmisikan secara lisan dari satu generasi ke generasi yang lebih muda. Situasi yang hampir sama juga terjadi di dalam kebudayaan Jawa. Tradisi lisan terlihat dari adanya mantra-mantra, pertunjukan wayang, resitasi macapat, dan sebagainya.

Tradisi kelisanan turut berperan besar dalam membentuk sastra Indonesia. Memang, pengaruhnya tak selalu buruk. Terdapat hal-hal positif yang diberikan.
Berkat adanya tradisi kelisanan, sejumlah karya menjadi karya-karya yang cukup monumental dan diterima penikmat sastra. Linus Suryadi Ag, WS Rendra, dan Sutardji Calzoum Bachri misalnya, merupakan contoh sastrawan-sastrawan yang kuat dalam bertumpu pada aspek kelisanan. Linus Suryadi Ag terkenal berkat karyanya yang berjudul Pengakuan Pariyem, sebuah prosa lirik yang jelas bertumpu pada pengolahan tradisi lisan. Di sisi lain, Rendra kondang dan dihormati sampai akhir hayatnya karena sajak-sajak baladanya yang keruan mengandung banyak unsur budaya lisan dan kepiawaiannya membaca sajak di pentas yang tak ayal merupakan praktik tradisi lisan. Sutardji dianggap banyak orang mencapai puncaknya dengan $O$, Amuk Kapak, sebuah antologi yang dengan terang menampakkan besarnya pengaruh kelisanan. Jika kita menyimak sajak-sajak yang mereka tulis akan terbaca bahwa mereka ternyata telah menguasai seluk-beluk bahasa tulis dengan mumpuni. Inilah kunci yang memungkinkan ketiganya berhasil mengolah unsur-unsur kelisanan jadi kekuatan puisi-puisi yang ditulis masingmasingnya (Hikmat Gumelar, http://indonesiabuku.com. Diakses tanggal 7 Januari 2011 pukul 23.21) 
Achadiati (dalam Pudentia (Ed), 2008:215) mengatakan bahwa eratnya keberaksaraan dengan kelisanan terlihat dalam pelisanan teks tulis dengan dipadukan dengan pembawaan lisani murni. Dalam pementasan seperti itu, dunia keberaksaraan dan kelisanan berbaur memenuhi fungsinya dengan sempurna. Adanya kelisanan yang tampak dalam puisi Indonesia modern ternyata juga tidak luput dari pengamatan A.Teeuw. Dikemukakan dalam bukunya yang berjudul Indonesia antara Kelisanan dan Keberaksaraan, puisi Indonesia menunjukkan kuatnya nilai dan tradisi teknik tradisional yang tetap didominasi oleh kelisanan. Pembacaan puisi di muka umum (dan kaset puisi untuk didengarkan) jauh lebih populer daripada kumpulan puisi dalam bentuk cetakan (Teeuw, 1994:vii). Dengan mengambil salah satu contoh karya sastra modern yang berjudul Pengakuan Pariyem, di dalam buku tersebut, Teeuw hanya menyoroti dan memperhatikan aspek kelisanan dalam hal pembacaan puisi. Aspek kelisanan yang ada di dalam teks sama sekali tidak dibicarakan Teeuw dalam buku tersebut. Masalah yang muncul dari pendapat Teeuw adalah bahwa ia hanya melakukan pengamatan terbatas pada teks verbal. Teks tulis yang tersedia ternyata luput dari pengamatan Teeuw

Berkait dengan persoalan di atas, Achadiati mengutip pendapat Lord (dalam Pudentia (Ed), 2008:214) yang menyatakan bahwa esensi kelisanan terletak pada aspek penyajiannya karena dalam peristiwa itulah terjadi aktualisasinya. Pada saat itulah seluruh kekuatan tradisi dihidupkan. Disitulah kita menyadari sifatnya yang sesaat; setiap tradisi itu, dihafalkan ia dapat berubah-ubah. Sebagai contoh, seorang dalang kentrung di saat penyajian mempertimbangkan lingkungannya, peristiwa yang dirayakan, khalayak, sehingga pementasannya unik, tidak akan dan tidak dapat diulang persis seperti yang terdahulu. Akan tetapi, bagi Albert B Lord, penelitian tradisi lisan tidak mungkin hanya membatasi diri pada teks verbal. Pengamatan kelisanan yang hanya bertumpu pada pengamatan pementasan terasa kurang sempurna. Aspek-aspek kelisanan yang terdapat di dalam teks tertulis sama pentingnya untuk dikaji dan dibahas. Oleh karena itu, di dalam tulisan ini apa yang telah diamati oleh Teeuw tersebut akan coba dilanjutkan dengan cara meneliti aspek-aspek kelisanan yang ada dalam teks Pengakuan Pariyem. Aspek kelisanan teks di dalam Pengakuan 
Pariyem karya Linus Suryadi Ag perlu untuk diungkapkan agar memungkinkan untuk memahami secara utuh pendapat Teeuw tersebut.

\section{Kerangka Teori}

Didalam penelitian ini digunakan dua teori. Yang pertama adalah teori kelisanan sedangkan yang kedua adalah teori hegemoni Gramsci. Teori kelisanan digunakan untuk menjelaskan aspekaspek kelisanan yang ada di dalam teks Pengakuan Pariyem sedangkan teori hegemoni Gramsci digunakan untuk menjelaskan aspek-aspek kelisanan itu dalam hubungannya dengan kebudayaan Jawa.

\subsection{Teori Kelisanan}

Untuk mempelajari situasi dalam sebuah budaya lisan primer dan tema yang hendak diteliti ini dalam kaitannya dengan budaya lisan, Ong menyarankan bahwa pertama-tama kita perlu merenungkan tentang sifat dari suara itu sendiri. Menurutnya, semua yang kita rasakan terjadi dalam rentangan waktu, tetapi suara memiliki beberapa ciri khusus yang berbeda dari hal-hal lain yang bisa dirasakan oleh pancaindra manusia. Suara tidak hanya tidak bisa bertahan lama, melainkan langsung lenyap dan dirasakan sebagai sesuatu yang langsung lenyap. Tidak ada cara untuk menghentikan suara dan menyimpan suara (Ong, 2002:3132).

Fakta bahwa sebagian besar atau bahkan mungkin sekali semua bangsabangsa yang masih berbudaya lisan menganggap kata-kata memiliki daya magis jelas terkait, setidak-tidaknya secara tidak sadar dengan pemahaman mereka bahwa kata harus diucapkan, disuarakan, dan harus ditopang dengan kekuatan. Orang-orang yang sudah berbudaya tipografis lalai untuk mengingat bahwa kata pada dasarnya adalah ucapan, sebuah kejadian, sehingga pada dasarnya harus selalu diberi tenaga. Alasannya, dalam pandangan orang-orang dari budaya tulis, kata selalu terikat pada benda tertentu dan selalu berada di luar dirinya, yaitu terletak pada permukaan datar. Benda-benda di mana kata-kata itu terletak tidak bisa dikuasai begitu saja dengan kekuatan, sebab kata-kata di atas permukaan datar itu bukan tindakan dan dalam artian tertentu bahkan bisa dianggap mati, sekalipun memang bisa dihidupkan lagi secara dinamis (Ong, 2002:32).

Menurut Ong (2002:33-34) dalam sebuah budaya lisan, kata dibatasi pada suara atau ucapan saja. Keterbatasan ini tidak hanya membatasi mode ekspresi, tetapi juga mempengaruhi proses berpikir. 
Dalam budaya lisan primer, untuk bisa menyimpan dan mengeluarkan kembali pikiran-pikiran yang sudah dibuat dengan seksama, harus berpikir dengan pola-pola mnemonik yang bisa dengan mudah dituangkan kembali ke dalam ucapan. Untuk itu perlu diciptakan dengan polapola yang berirama, seperti berpikir dalam bentuk perulangan atau antitesis, aliterasi atau asonansi, menggunakan julukan-julukan atau ekspresi-ekspresi baku lainnya, atau dengan pola-pola mnemonik lainnya. Buah pikiran yang serius selalu terkait dengan sistem ingatan yang digunakan. Dalam pandangan Ong, formula sangat membantu untuk membuat sebuah wacana yang bersajak dan juga sekaligus berfungsi sebagai alat bantu mengingat, yaitu sebagai frase-frase baku yang diucapkan dan didengarkan oleh semua orang dalam sebuah budaya. Berpikir panjang tidak mungkin dilakukan tanpa bantuan ekspresi-ekspresi baku atau formula semacam ini, sebab buah pemikiran itu dituangkan ke dalam ekspresi baku atau formula itu sendiri.

Dalam sebuah budaya lisan, pikiran yang dibuat dengan cara seperti itu tidak bisa menjadi lebih dari sekedar khayalan yang tak berguna, betapapun rumitnya pemikiran itu. Pola-pola baku dan formula-formula yang digunakan secara bersama di dalam sebuah budaya yang tidak mengenal tulisan memiliki fungsi seperti tulisan di dalam budaya-budaya khirografis, tapi penggunaan pola-pola baku dan formula itu mempengaruhi pola pikir yang bisa mereka lakukan, yaitu mempengaruhi cara pengorganisasian secara intelektual terhadap pengalaman mereka. Dalam sebuah budaya lisan, pengalaman diintelektualisasikan atau dijadikan pengetahuan dengan menggunakan alat bantu ingatan (Ong, 2002:35).

Di dalam lingkungan budaya lisan, mempelajari atau mengetahui sesuatu berarti melakukan identifikasi secara dekat, secara empatis, dan secara komunal dengan apa yang dipelajari atau diketahuinya itu. Dengan kata lain, dalam sebuah budaya lisan terdapat upaya-upaya untuk "merasuk ke dalamnya". Sebaliknya, tulisan memisahkan antara pihak yang mengetahui dari apa yang diketahui sehingga memungkinkan kita untuk bersikap objektif. Artinya, ada suatu kebebasan untuk melepaskan atau menjauhkan diri kita dari apa yang diketahui itu. Objektivitas yang dimiliki oleh para penyaji lisan lainnya adalah objektifitas yang ditimbulkan sebuah ekspresi formula. Dalam konsep ini, reaksi individu tidak dinyatakan sebagai 
reaksi individu atau reaksi subjektif, melainkan dinyatakan sebagai reaksi komunal, atau sebagai jiwa komunal. Oleh sebab itu, menurut Ong (dalam Teeuw, 1994:27) dalam kebudayaan lisan karya sastra pun bersifat parsipatoris. Parsipatoris berarti bahwa dari sidang pendengar diharapkan sikap "peran serta", identifikasi, sikap, dan sambutan kolektif.

Dalam penjelasan yang lebih mudah, pendapat di atas dapat diartikan bahwa budaya tulis membangun keberjarakan sedangkan budaya lisan menuntut keterlibatan. Setiap orang harus menghamburkan dirinya dalam tindakan, bukan refleksi dan kontemplasi. Segala sesuatu dibangun, dipelihara, dan bahkan diubah dalam komunikasi tatap muka, dalam pergaulan sosial, bukan dalam kesendirian seorang ilmuwan yang berdiam di keheningan laboratorium (Faruk, 2000:36-37)

Menurut Ong ( 1977:278) tidak secara kebetulan terbentuk bahwa kebudayaan lisan sangat mementingkan aspek mimesis. Mimesis dalam konsep ini adalah berarti upaya meniru, upaya meneladan, upaya membayangkan, dan sebuah upaya merepresentasikan. Oleh karena itu, tolok ukur estetik pertama ialah sejauh mana gambar atau tiruan itu sesuai dengan kenyataan (Luxemburg dkk. 1989:19). Dalam kebudayaan lisan tidak ada originalitas, dalam arti seorang sastrawan atau manusia lainnya mencipta secara individual sesuatu yang baru. Peneladanan alam, representasi kenyataan, adalah tugas utama seorang sastrawan. Oleh karena itu, penciptaan karya selalu berarti meneladani kenyataan dan/atau meniru konvensi penciptapencipta sebelumnya.

\subsection{Teori Hegemoni Gramsci}

Gramsci menganggap dunia gagasan, kebudayaan, superstruktur, bukan hanya sebagai refleksi atau ekspresi dari struktur kelas ekonomik, atau infrastruktur yang bersifat material, melainkan sebagai salah satu kekuatan material itu sendiri. Sebagai kekuatan material itu, dunia gagasan atau ideologi berfungsi mengorganisasi massa manusia, menciptakan suatu tanah lapang yang di atasnya manusia bergerak. Bagi Gramsci, hubungan antara yang ideal dengan yang material tidak berlangsung searah, melainkan bersifat saling tergantung dan interaktif, kekuatan material merupakan isi, sedangkan ideologi-ideologi merupakan bentuknya. Kekuatan material tidak akan dapat dipahami secara historis tanpa bentuk, dan ideologi-ideologi akan 
menjadi khayalan individual belaka tanpa kekuatan material (Faruk, 1994:61-62).

Bagi Gramsci, persoalan kultural dan formasi ideologis menjadi penting karena didalamnya terdapat proses yang rumit. Gagasan-gagasan dan opini tidak lahir begitu saja dari otak individual, melainkan mempunyai pusat formasi, irradiasi, penyebaran, dan persuasi. Kemampuan gagasan/opini menguasai seluruh lapisan masyarakat merupakan puncaknya. Puncak tersebutlah yang disebut oleh Gramsci sebagai hegemoni (Faruk, 1994: 62). Hegemoni sebuah kelas politik mengandung pengertian bagi Gramsci bahwa kelas tersebut telah berhasil membujuk kelas-kelas lain dalam masyarakat untuk menerima nilai-nilai moral, politik, maupun kulturalnya. Dengan demikian, budaya yang tersebar merata di dalam masyarakat pada waktu tertentu dapat diinterpretasikan, dari sudut pandang ini, sebagai suatu hasil atau perwujudan hegemoni, perwujudan dari penerimaan "konsensual” oleh kelompokkelompok gagasan subordinat, nilai-nilai, dan kepemimpinan kelompok dominan tersebut (Strinati, 2009:255).

Teori Gramsci mengemukakan bahwa kelompok-kelompok subordinat menerima gagasan, nilai-nilai, maupun kepemimpinan kelompok dominan tersebut bukan disebabkan secara fisik atau mental mereka dibujuk atau melakukannya, juga bukan disebabkan mereka diindoktrinasi secara ideologis, melainkan karena mereka punya alasanalasan tersendiri. Gramsci memandang hegemoni sebagai salah satu aspek kontrol sosial yang muncul dari konflik sosial. Hegemoni bukanlah suatu perintah fungsionalisme kapitalisme, melainkan merupakan sekumpulan gagasan konsensual yang berada dari dan membentuk kelas maupun konflik-konflik sosial lainnya. Hegemoni mengekspresikan persetujuan terhadap otoritas wacana kelompok dominan dalam masyarakat. Dengan demikian, hegemoni diterima dan berfungsi karena dalam pengertian umum didirikan atas jaminan konsesi kepada kelompokkelompok subordinat yang tidak memberikan ancaman terhadap kerangka dominasi secara keseluruhan (Strinati, 2009:256-257).

Ada perbedaan konsep Gramsci dengan marxisme ortodoks. Jika marxisme ortodoks menekankan pentingnya peranan represif dari negara dan masyarakat-masyarakat kelas, Gramsci memperkenalkan dimensi "masyarakat sipil" untuk melokasikan cara-cara yang kompleks yang secara 
inheren "kesetujuan" pada bentuk-bentuk dominasi produksi. Dimensi ekstra hegemoni inilah yang mempermudah Gramsci merumuskan kembali pertanyaan menyeluruh mengenai hubungan antara kelas dengan kebudayaan, mengisyaratkan cara-cara yang dengannya tanah lapang kebudayaan menjadi suatu medan strategis pembangunan bentuk-bentuk kesepakat-an. Melalui hak itu pula, bentuk-bentuk ideologis dan kultural secara historis dinegosiasikan antara kelompok-kelompok dominan dengan subordinat (Faruk, 1994:63).

Dengan demikian, bagi Gramsci, ada suatu pertalian yang penting antara kebudayaan dengan politik, tetapi pertalian itu jauh daripada pertalian yang sederhana dan mekanik. Kebudayaan harus dipecah-pecah menjadi berbagai macam bentuknya, entah kebudayaan "tinggi" atau "rendah", kebudayaan elit atau popular, filsafat atau common sense, dan dianalisis dalam batas-batas efektivitasnya dalam "penyemenan" bentuk-bentuk kepemimpinan yang kompleks (Faruk, 1994: 63-64).

Gramsci, seperti diungkapkan oleh Strinati (2009: 262), mengatakan bahwa hegemoni bukanlah seperangkat gagasan pasti dan tetap yang memiliki suatu fungsi yang konstan. Menurut Gramsci, sekalipun jelas-jelas hegemoni berfungsi mengamankan dominasi kelas-kelas maupun kelompok-kelompok yang paling kuat di dalam masyarakat, dan mendapat perhatian ketika begitu dominan sampaisampai mewarnai apa yang disebut sebagai "akal sehat", bagaimana pun juga hegemoni merupakan sesuatu yang berasal dari perjuangan kelas maupun sosial yang pada gilirannya berfungsi membentuk dan memengaruhi. Oleh karena itu, cengkeraman hegemoni atas kelompok-kelompok subordinat pada praktiknya tidak bisa dijamin sepenuhnya.

\section{Metode Penelitian}

Langkah-langkah penelitian yang dilakukan dalam penelitian ini meliputi pembacaan karya sastra, pemilihan data dalam teks, analisis data, dan penarikan kesimpulan. Pembacaan objek penelitian dilakukan dengan cermat dan detail terhadap fenomena-fenomena kelisanan yang mungkin dapat dijadikan data. Setelah melalui tahap tersebut, sejumlah data yang terdapat di dalam teks diangkat sebagai data penelitian dan dianalisis berdasarkan teori kelisanan Walter J Ong. Konsep-konsep teori kelisanan Walter J Ong yang diterapkan antara lain konsep parsipatoris, mimesis/peneladanan, dan 
perulangan. Tahap analisis masih perlu dilakukan karena setelah melalui tahap analisis kelisanan, masih terlihat suatu fenomena menarik, yaitu adanya bingkai hegemoni dalam penerapan konsep mimesis/peneladanan dan keparsipatorisan yang ditunjukkan oleh tokoh Pariyem di dalam teks. Oleh sebab itu, dioperasikan konsep hegemoni Gramsci untuk mendeskripsikan gejala itu. tahap akhir penelitian ini kemudian adalah penarikan kesimpulan berdasarkan analisis data berdasarkan teori kelisanan Walter J. Ong dan teori hegemoni Gramsci.

\section{Pembahasan}

\subsection{Aspek Kelisanan dalam Teks Pengakuan Pariyem}

Di dalam teks Pengakuan Pariyem terdapat beberapa unsur kelisanan yang sangat menonjol. Terlepas dari aspek kelisanan yang berwujud pada segi pementasan karya di panggung seperti yang dikemukakan oleh Teeuw (1994), Pengakuan Pariyem juga memperlihatkan aspek kelisanan di dalam teks. Penciptaan Pengakuan Pariyem yang meneruskan unsur-unsur sastra Jawa dianggap turut memberikan pengaruh yang besar dalam meninggalkan jejak-jejak kelisanan. Dibawah ini akan dibahas beberapa aspek

kelisanan yang cukup menonjol.

\subsubsection{Bentuk-Bentuk Perulangan sebagai Sebuah Kelisanan}

Teks Pengakuan Pariyem

memperlihatkan begitu banyak bentukbentuk pengulangan. Suatu bentuk atau pola pada bagian tertentu, dimunculkan kembali oleh Linus dengan bentuk yang hampir sama pada bagian yang berbeda. Sebagai contoh, Linus acapkali memakai bentuk-bentuk pengulangan untuk menjelaskan identitas tokoh Pariyem. Suatu kalimat yang berbunyi $Y a, y a$ Pariyem sayall Maria Magdalena Pariyem lengkapnya//"Iyem" panggilan sehari-harinya // Dari Wonosari Gunung Kidul// Sebagai babu nDoro Kanjeng Cokro Sentono diulang-ulang secara acak pada bagian-bagian yang berbeda. Namun, pengulangan pada tempat-tempat yang berbeda itu masih dalam bentuk yang sangat mirip. Hal ini menunjukkan ada semacam suatu paragraf yang siap pakai di dalam teks. Artinya, suatu paragraf yang telah menjadi bentuk dan pola baku dalam teks tersebut.

"Ya, ya Pariyem saya
Maria Magdalena Pariyem
lengkapnya
Iyem panggilan sehari-harinya
Dari Wonosari Gunung Kidul
Sebagai babu nDoro Kanjeng
Cokro Sentono


(Suryadi Ag, 2002:29)

"Ya, ya Pariyem saya

Maria Magdalena Pariyem

lengkapnya

Iyem panggilan sehari-harinya

Dari Wonosari Gunung Kidul

Sebagai babu nDoro Kanjeng

Cokro Sentono

( Suryadi Ag, 2002: 31)

"Ya, ya Pariyem saya

Maria Magdalena Pariyem lengkapnya

Iyem panggilan sehari-harinya

Dari Wonosari Gunung Kidul

Sebagai babu nDoro Kanjeng

Cokro Sentono

(Suryadi Ag, 2002:33)

Dari ketiga kutipan di atas, dapat dilihat bahwa bentuk-bentuk yang sama diulang-ulang layaknya sebuah paragraf yang siap pakai dan baku. Ketika kalimatkalimat itu dimunculkan kembali secara acak pun, tidak terdapat satu pun perbedaan. Perbedaan satu bagian dengan bagian yang lain sama sekali tidak tampak. Bentuk di atas berulang dan sama pada beberapa bagian, yaitu pada halaman 34, 37, 58, 62, dan seterusnya. Meskipun demikian, dalam tempat tertentu Linus juga menuliskan kalimatkalimat di atas ke dalam bentuk yang sedikit berbeda. Akan tetapi perbedaan itu tidak bersifat esensial.

"Ya, ya Pariyem saya

Maria Magdalena Pariyem lengkapnya

Iyem panggilan sehari-harinya

Dari Wonosari Gunung Kidul
Saya suka membayangkan diri saya (Suryadi, Ag: 2002: 22).

"Pariyem saya

Maria Magdalena Pariyem lengkapnya

Iyem panggilan sehari-harinya

Dari Wonosari Gunung Kidul

Sebagai babu nDoro Kanjeng

Cokro Sentono

(Suryadi Ag, 2002:40)

"YaPariyem saya

Maria Magdalena Pariyem lengkapnya

Iyem panggilan sehari-harinya

Di Wonosari Gunung Kidul

Tata lahirnya, saya hanya babu

Tapi batinnya saya selir baru

(Suryadi Ag, 2002:201)

Beberapa kutipan di atas jika diperbandingkan terlihat ada suatu perbedaan. Namun, perbedaan kalimat pada kutipan-kutipan di atas tidak menimbulkan adanya perbedaan dalam hal esensi dan informasi. Secara tekstual kutipan halaman 40 dan halaman 22 hanya terletak pada kalimat pertama, yaitu "Ya, ya Pariyem saya (hlm. 22) dengan kalimat pertama pada halaman 40 yang dituliskan "Pariyem saya". Perbedaan tersebut jelas bukanlah perbedaan yang mengacaukan referensi karena yang diacu oleh keduanya (hlm. 40 dan hlm. 22) masih tetap, yaitu tokoh Pariyem yang berasal dari Wonosari, Gunung Kidul.

Bentuk pengulangan yang ada 
dalam Pengakuan Pariyem tidak hanya itu. Selain pengulangan bentuk kalimatkalimat yang menunjukkan identitas diri, pengulangan dalam bentuk lain juga ada. Sebagai contoh, kalimat $O$ Allah Gusti nyuwun ngapura berkali-kali muncul di dalam teks. Kalimat itu digunakan untuk menyatakan perasaan tokoh Pariyem mengenai sesuatu pergulatan batin yang ia temui kepada "Mas Paiman". Pergulatan batin Pariyem berontak manakala dirinya menemui sesuatu yang tidak pas dalam konteks adat dan aturan norma Jawa. Dan pada saat itulah kalimat tersebut muncul (hlm. 60, hlm. 54, hlm. 86, hlm.49, dst).

\subsubsection{Parsipatoris sebagai Jejak Kelisanan}

Salah satu aspek kelisanan yang terlihat di dalam teks setelah adanya bentuk-bentuk pengulangan adalah adanya sifat parsipatoris. Aspek parsipatoris ditunjukkan lewat kepiawaian Linus dalam menghidupkan tokoh Pariyem ketika bercerita mengenai dirinya kepada "Mas Paiman". Tokoh Pariyem seolah-olah bercerita pada orang lain, yang sebenarnya merujuk kepada pembaca. Di sinilah ada kemungkinan menciptakan sebuah interaksi dengan membangun sebuah komunikasi yang nirjarak. Seolah-olah jarak antara pembaca dan tokoh Pariyem diluruhkan oleh gaya bercerita Pariyem. Pada saat Pariyem akan menceritakan dunia batinnya dan beberapa pengalamannya menjadi babu di nDalem Suryamentaraman, termasuk saat dirinya berhubungan dengan Den Ario Atmojo, ia (tokoh Pariyem) bercerita layaknya seseorang yang sedang bertutur.
"Ya, ya Pariyem saya
Maria Magdalena Pariyem lengkapnya
Iyem panggilan sehari-harinya
Dari Wonosari Gunung Kidul
Sebagai babu nDoro Kanjeng Cokro Sentono
Di nDalem Suryomentaraman Ngayogyakarta
Saya mengaku kepada Mas Paiman
Dan tidak kepada orang lain kok Habis, jaman sekarang orang sukar dipercaya

(Suryadi Ag, 2002:58—59)

Kedekatan dan ketidakberjarakan tokoh Pariyem dan pembaca dijalin dengan beberapa cara. Pertama, seolaholah tokoh Pariyem di dalam teks bercerita dan sedang mencurahkan segala isi batinnya kepada pembaca yang "diberi nama" dengan sebutan "Mas Paiman". Tampaknya, upaya ini adalah suatu cara untuk menyiasati jarak yang mungkin tercipta antara tokoh Pariyem dengan pembaca. Melalui "pemberian nama" Mas Paiman, ada sebuah celah untuk merapatkan interaksi emosi antara 
pembaca dengan tokoh Pariyem. Selain itu, untuk memperjelas masalah interaksi, tokoh Pariyem menggunakan kata "saya" untuk menyebut dirinya di dalam teks. Hal ini juga bukan tanpa alasan karena dengan penggunaan kata itu, seolah-olah gaya tutur tokoh Pariyem seperti komunikasi dua arah yang erat dengan sebuah keterlibatan. Artinya, ada interaksi yang lebih antara "Mas Paiman" dengan tokoh Pariyem. Akibat adanya interaksi dan komunikasi dua arah ini maka di dalam teks juga terlihat gaya bercerita Pariyem seperti halnya seseorang yang sedang bercakap-cakap secara verbal dengan "Mas Paiman".

“Ah, Mas Paiman

Lihatlah sekarang

Bila saya menerjemahkan bahasa Jawa

Ke dalam bahasa Indonesia

Yakni, bahasa persatuan kita

Ialah bahasa kebangsaan kita

Maka saya korupsi bahasa

Saya memanipulasi kebudayaan

Saya pun setlika peradaban

Wuahh, saya berprokol bambu

Yang tak genah juntrungannya

Bahasa Jawa bangkrut maknanya

Sedang bahasa Indonesia jaya

(Suryadi Ag, 2002:44-45)

Rapatnya interaksi antara "Mas

Paiman" dengan tokoh Pariyem seolaholah membuat mereka disatukan dalam sebuah dimensi yang sama. Antara Pariyem dan "Mas Paiman" tidak terpisahkan oleh sekat-sekat tekstual maupun keberjarakan. Oleh karena itu, ketika tokoh Pariyem sedang menceritakan dirinya, ia menganggap dirinya sedang berhadapan dengan "Mas Paiman", sedang mengobrol, atau juga layaknya saat sedang bercengkerama pada suatu wilayah yang begitu intim. Sangat rapat dan menihilkan jarak. Adanya suatu interaksi yang rapat itu kadang-kadang di dalam teks tokoh Pariyem menyatakan ada sebuah forum antara dirinya dengan "Mas Paiman" melalui pemakaian kata kita. Penggunaan kata "kita" menunjukkan jarak antara pembaca dengan alur cerita tidak lagi ada, terganti oleh suasana interaktif yang terjalin di dalam teks tersebut.

"sedangkan saya pantang berdusta Bila saya dusta pada orang lain Orang lain akan dusta sama saya Saya kuwalat Saya kena hukum karma namanya Bila saya dusta sama lain orang Saya dikuntit oleh rasa berdusta Saya tak ayem tentrem karenanya Saya tak krasan ketemu siapa saja Bila saya nekad terus-terusan berdusta

Saya hidup dalam kubangan neraka namanya

Bukankan neraka, begitu kata orang-orang tua

Adalah api kekal yang menggoreng batin kita?

(Suryadi Ag, 2002:60)

\subsubsection{Peneladanan Kaum Priyayi sebagai Sebuah Mimesis}




\section{Ketokohan}

Aspek kelisanan yang selanjutnya adalah peneladanan atau mimesis. Peneladanan yang dimaksud dalam hal ini adalah peneladanan sosok manusia Jawa dalam pandangan tokoh Pariyem. Hal ini penting karena di dalam teks tersebut, kultur Jawa tokoh Pariyem sangat kuat. Oleh karena itu, sosok ideal yang patut jadi panutan dan teladan bagi Pariyem adalah para priyayi yang terdiri dari nDoro Kanjeng, nDoro Ayu, nDoro Putri, dan Den Bagus Ario Atmojo. Pariyem pun secara sadar tidak peduli apabila sifat-sifat para majikannya yang berasal dari kelas priyayi itu tidak sepenuhnya ideal. Terlebih pada tokoh nDoro Kanjeng, tokoh Pariyem menempatkan tokoh tersebut sebagi suatu model ideal seorang lelaki Jawa.

"Kanjeng Raden Tumenggung
gelarnya
Putra Wijaya nama timurnya
Cokro Sentono nama dewasanya
nDoro Kanjeng panggilannya
Priyagung Kraton Ngayogyakarta
Priyayinya jangkung, tubuhnya
gede
Dia punya katuranggan Raden
Werkudara
....
Apabila berjalan
Sak titahe, tak bergegas
Mengikuti irama jagad dalam
Itulah jiwa Jawa, mas:
Alon-alon waton kelakon
Tetapi semua pekerjaannya beres

(Suryadi Ag, 2002: 64)

Lihat pula kutipan selanjutnya.

Wawasannya luas

Seluas Alun-alun Lor

Hatinya longgar

Selongggar kathok kolor

Pikirannya tajam

"nDoro Kanjeng wong wicaksono, lho

Sering benar dimintai wejangan:

(Suryadi Ag, 2002:65)

Peneladanan pada tokoh nDoro Kanjeng tampaknya juga sedikit membabi buta. Di dalam teks sebenarnya juga dikemukakan bahwa nDoro Kanjeng pada waktu berusia muda juga ugal-ugalan, memiliki banyak wanita selir, dan beberapa hal negatif lainnya (hlm. 192). Akan tetapi bagi tokoh Pariyem, hal itu tidak jadi soal. Menurut tokoh Pariyem, keburukan nDoro Kanjeng pada waktu usia muda telah tertutup dengan sikap dan kematangannya sebagai lelaki Jawa (hlm. 66-67). Persoalan peneladanan tidak hanya terjadi kepada tokoh nDoro Kanjeng. Kepada tokoh nDoro Ayu dan nDoro Putri pun, Pariyem memiliki hasrat untuk meneladani. Tokoh nDoro Ayu menurut Pariyem merupakan sosok wanita anggun yang luhur budinya, sosok yang agung sebagai wanita Jawa, dan prototipe ideal seorang istri (hlm. 115). Di lain pihak, menurut Pariyem, tokoh 
nDoro Putri adalah tipe wanita yang cukup ideal dalam lingkungan budaya Jawa modern. Tokoh nDoro Putri merupakan sosok yang intelektual, modern, dan masa kini (hlm. 136), tetapi masih memegang adat dan nilai-nilai budaya Jawa dengan kuat (hlm.153155). Sosok seperti itulah yang memikat hati Pariyem. Dalam hal kepribadian pun, sosok perempuan Jawa yang ideal adalah sosok yang lembah manah dan andhap asor seperti layaknya seorang putri kraton.

"Ya, ya Pariyem saya

Maria Magdalena Pariyem lengkapnya

"Iyem" panggilan sehari-harinya

Dari Wonosari Gunung Kidul

Saya tak suka serba kaku—ngotot-

Bagaikan baja yang keras tapi getas

Sekali bengkok tak punya gaya pegas

Saya suka serba luwes_-lembut-

Bagaikan putri kraton

Ngayogyakarta

Yang lembah manah dan andhap asor

Tenang, bagaikan air kolam

Memantulkan sinar rembulan

(Suryadi Ag, 2002:21)

\subsection{Parsipatoris dan Mimesis dalam Bingkai Hegemoni Kelas Feodal Jawa}

Pembahasan dalam subbab ini bertujuan untuk mendeskripsikan hubungan antara jejak kelisanan dalam teks yang berupa parsipatoris dan peneladanan terhadap kelas feodal masyarakat Jawa oleh Pariyem. Jika diperhatikan di dalam teks terlihat bahwa terdapat stratifikasi sosial dalam masyarakat yang berupa hubungan kelas priyayi-rakyat biasa. Kelas priyayi di dalam teks diwakili oleh nDoro Kanjeng beserta keluarganya sedangkan kaum proletar diwakili oleh tokoh Pariyem beserta lingkungannya pula. Relasi oposisi antara kelas priyayi dan proletar menyebabkan keduanya terpisah oleh status sosial masing-masing. Oleh karena itu, dalam gaya parsipatoris yang kental, tokoh Pariyem hanya berinteraksi secara emosi, dalam arti menceritakan pengalaman batinnya, hanya kepada "Mas Paiman" yang notabene berasal dari kelas sosial yang sama (hlm. 141 dan hlm. 27). Di dalam teks sama sekali tidak terlihat bahwa tokoh Pariyem menceritakan pergulatan batinnya dengan tokoh selain "Mas Paiman". Fakta ini menunjukkan bahwa "Mas Paiman" adalah tokoh yang paling dekat dengan Pariyem dalam tuturan atas segala uneg-unegnya.

Ya, ya Pariyem saya

Maria Magdalena Pariyem lengkapnya

Iyem panggilan sehari-harinya

Dari Wonosari Gunung Kidul

Sebagai babu nDoro Kanjeng Cokro Sentono

Di nDalem Suryomentaraman Ngayogyakarta 
Saya mengaku kepada Mas Paiman Dan tidak kepada orang lain kok

Habis, jaman sekarang

orang sukar dipercaya

(Suryadi Ag, 2002:58-59)

Kutipan di atas menunjukkan bahwa persamaan kelas merupakan elemen yang penting dalam hal partisipasi. Antara "Mas Paiman" dan Pariyem berada di kelas yang sama. Oleh karena itu, peluang bagi Pariyem untuk secara leluasa berinteraksi dan berkomunikasi dengan "Mas Paiman" sangat besar. Hal sebaliknya akan terjadi apabila Pariyem menceritakan pengalaman batinnya kepada keluarga nDoro Kanjeng. Ada kemungkinankemungkinan ekspresi tutur Pariyem tidak seleluasa jika bertutur kepada "Mas Paiman" karena antara Pariyem dengan keluarga nDoro Kanjeng terpisahkan oleh kelas sosial. Dengan demikian, di dalam teks tersebut dapat dikatakan bahwa Pariyem memilih "Mas Paiman" sebagai partisipannya dilakukan secara sadar. Pariyem menemukan ekspresi batin yang sama ketika ia menuturkan pada "Mas Paiman" yang sekelas sosial dengannya, bukan dengan golongan kaum priyayi.

Saya dengar dan saya resapkan Pun saya resapkan ke dalam kalbu --sebagai pesugihan batin Ah, ya jika saya suka ngomong Bukan maksud saya mulang sampeyan
Terang, saya tak punya pendidikan Saya pun tak pantas kasih wulangan

Tak sebagaimana kaum priyayi kota Tak sebagaimana orang muda dusun (Suryadi Ag, 2002: 105-106)

Dengan demikian, dari kutipan di atas, dapat disimpulkan bahwa partisipan bagi Pariyem yang paling ideal adalam "Mas Paiman". Kenyataan itu disebabkan proses penuturan batin Pariyem akan lebih leluasa karena antara "Mas Paiman" dan Pariyem mempunyai identitas dan kelas yang sama, yaitu proletar. Tentu saja permasalahan identitas kelas menjadi penting dalam hal ini karena stratifikasi sosial tersebut menentukan partisipan bagi Pariyem.

Pada aspek yang lain, yaitu pada aspek mimetik, justru terjadi sebaliknya. Dalam hal keteladanan, Pariyem memandang bahwa kehidupan priyayi dan kraton adalah teladan yang ideal. Secara sadar, Pariyem memilih keluarga nDoro Kanjeng sebagai sebuah model keluarga Jawa yang ideal. Di dalam persoalan ini, "Mas Paiman" yang berasal dari entitas dan kelas yang sama dengan Pariyem benar-benar tidak mendapat tempat. Model keteladanan bagi Pariyem mengenai keluarga Jawa benar-benar berorientasi pada kehidupan keluarga priyayi, baik itu dalam hal wanita yang 
diidealkan seperti putri kraton (hlm. 115), lelaki, maupun teladan keluarga ideal secara utuh. Situasi itu muncul disebabkan dalam pandangan Pariyem, kaum priyayi adalah orang-orang yang berkedudukan istimewa, berbeda dengan dirinya, atau bahkan dengan "Mas Paiman".

Tapi Den Baguse tak menolak lho Ia tenang, gagah dalam pakaian Jawa

Iapun membawakan tiga pupuh Tripama

Karya besar Sri Mangkunegara IV Yang menunjukkan papan dunungnya

Sebagai priyagung utama jatmika (Suryadi Ag, 2002:209)

Pandangan Pariyem tersebut sekaligus menempatkan priyayi sebagai manusia "tanpa cela" walaupun ada sesuatu yang buruk telah dilakukan di masa lalu seperti halnya dialami oleh nDoro Kanjeng (hlm. 192). Untuk Pariyem, hal itu tidak jadi soal. Dengan demikian, ada beberapa hal yang patut dicatat di sini. Pertama, dalam hal memilih pertisipannya, Pariyem memilih "Mas Paiman" secara sadar karena alasan-alasan yang ideologis. Di antaranya disebabkan oleh kelas yang sama. Kedua, berbanding terbalik dengan yang pertama, dalam hal peneladanan Pariyem justru secara sadar memilih keluarga nDoro Kanjeng sebagai model keluarga teladan, bukan "Mas Paiman". Ketiga, berdasarkan pengamatan dua hal di atas dapat dikatakan bahwa terdapat hegemoni kelas di dalam teks Pengakuan Pariyem. Antara Pariyem dan keluarga nDoro Kanjeng terpisahkan oleh sekat ideologis yang membatasi relasi antarmereka.

Ah, ya, maklum Jawa Baru, mas

Semua serba pakai kelas

Bangsawan dan rakyat jelata

Darah biru dan darah biasa

Dalam kraton dan luar kraton

Berbeda derajatnya

Kehormatan serta kedudukannya

(Suryadi Ag, 2002:6)

Pada tingkat yang paling tinggi hal itu terlihat ketika Pariyem hamil, ia tidak diresmikan sebagai seorang istri bagi Den Ario Atmojo. Pariyem merasa ikhlas tidak dinikahi oleh majikannya walaupun dirinya tengah mengandung keturunan majikannya (hlm. 181 dan hlm. 191). Kedudukan sebagai seorang selir sudah cukup pantas untuknya (hlm. 215). Persoalan tersebut muncul karena relasi kelas sosial yang berbeda mengakibatkan tidak luwesnya hubungan antara tokoh Den Ario Atmojo dan tokoh Pariyem sehingga mereka pun tidak diresmikan menjadi seorang suami-istri. Lebih-lebih, persoalan itu makin mencuat ketika di dalam teks digambarkan tokoh Endang (anak antara Den Ario Atmojo dengan 
Pariyem) telah lahir dan berusia beberapa bulan. Kehidupan Pariyem kembali seperti sediakala. Ia tetap menjadi babu di nDalem Suryamentaraman sedangkan Den Ario Atmojo tetap sebagai majikannya.

Dua tempat satu jagad

Dua tempat satu nyawa

O, di sini saya hidup

Di sini saya bercinta

Mas Paiman, O Mas Paiman

Saya tetap tinggal sebagai sediakala

Saya tetaplah babu yang setia

Sebagai babu nDoro Kanjeng

Cokro Sentono

Di nDalem Suryamentaraman

Ngayogyakarta

Tak kurang suatu apa

Saya sudah bahagia

(Suryadi Ag, 2002: 232)

Kutipan di atas menunjukkan bahwa hegemoni di dalam teks terlihat sangat mantap. Hubungan antara majikan dan buruh (Ndoro Kanjeng dan Pariyem) bersifat tegas dan jelas, tidak saling tumpang tindih. Meskipun demikian, terdapat negosiasi atas hubungan majikan dan bawahan seperti halnya terjadi pada Ndoro Kanjeng dan Pariyem. Salah satu negosiasi yang tercermin di dalam teks terlihat ketika Ndoro Kanjeng memberikan wejangan kepada Pariyem. Di dalam wejangan itu, Ndoro Kanjeng mengatakan bahwa antara priyayi dan rakyat biasa tidak berbeda. Jabatan bukanlah segala-galanya (hlm.68). Suatu upaya yang sama juga tampak pada pikiran Pariyem. Menurut Pariyem yang dituturkan kepada "Mas Paiman", selalu ada dikotomi bangsawan dan rakyat biasa, tetapi hal itu tidak ada bedanya. Walaupun berbeda, tetapi kodrat keduanya adalah satu, saling membutuhkan (hlm. 29). Upaya yang paling nyata tampak dengan pikiran Pariyem dalam menegosiasikan oposisi kelas bangsawan dan rakyat biasa dengan tuturannya yang mengatakan bahwa pangkat bukan ukuran, akan tetapi martabatlah yang menentukan kedudukan.

Tapi pangkat bukan ukuran Yang menakar martabat insan Karena peran dan kewajiban Pangkat pun kita sandang (Suryadi Ag, 2002:30)

Kutipan di atas memperlihatkan adanya situs-situs negosiasi di dalam teks Pengakuan Pariyem. Negosiasi-negosiasi itu seperti halnya mengamuflasekan oposisi antara priyayi dan rakyat jelata, atau memosisikan kaum jelata sejajar dengan kaum bangsawan. Akan tetapi, pada kenyataannya selalu ada dominasi kaum priyayi terhadap kaum jelata. Seperti halnya yang terjadi dengan tokoh Pariyem. Sepenting apapun dia bagi Den Ario Atmojo dan keluarga nDoro Kanjeng, bahkan telah memberikan cucu 
kepada majikannya, ia tetaplah sebagai pembantu. Tidak lebih dari itu. Dengan demikian, hubungan cinta ataupun relasi kekeluargaan bisa saja terjadi dengan sangat akrab antara kaum bangsawan dan rakyat jelata, akan tetapi hal itu tidak mengubah status sosial masing-masing. Seperti halnya di dalam teks, tokoh Pariyem tetaplah Pariyem yang berstatus sebagai babu bagi keluarga Ndoro Kanjeng. Begitu pula dalam hubungannya dengan Den Ario Atmojo. Seintim apapun Pariyem mampu menjalin hubungan intim dengan Den Ario Atmojo, tetapi ia tetaplah berstatus sebagai majikan bagi Pariyem.

\section{Penutup}

Setelah analisis terhadap teks Pengakuan Pariyem maka didapat beberapa kesimpulan. Paling tidak ada tiga aspek kelisanan yang terdapat di dalam teks Pengakuan Pariyem. Pertama, aspek kelisanan yang terlihat dalam penggunaan bentuk-bentuk yang berulang. Bentuk-bentuk yang berulang itu seperti halnya paragraf yang siap pakai dan digunakan di berbagai bagian dalam teks dengan bentuk yang sama. Memang, dalam praktiknya juga ditemukan adanya perbedaan kecil dalam paragraf siap pakai itu. Akan tetapi, perbedaan yang ada dalam bentuk perulangan itu tidak mengubah esensi dan informasi karena perbedaannya sangat kecil. Kedua, terdapat aspek kelisanan yang berupa sifat-sifat parsipatoris. Sifatsifat parsipatoris terlihat dari gaya penuturan Pariyem yang berusaha membangun kedekatan emotif dan interaksi dengan "Mas Paiman” yang tak lain adalah pembaca. Keterlibatan pembaca terhadap alur cerita yang coba dikembangkan oleh Linus mengindikasikan ada sebuah usaha meleburkan jarak antara pembaca dan karya dalam satu dimensi tertentu. Ketiga, aspek kelisanan yang lain adalah mimesis atau peneladanan. Mimesis yang ada berupa peneladanan terhadap konsepkonsep keluarga maupun sikap-sikap hidup yang ideal yang bersumber dari golongan kaum priyayi kraton.

Berdasarkan analisis unsur kelisanan tersebut yang kemudian dihubungkan dengan teori hegemoni Gramsci maka juga didapatkan sebuah kesimpulan yang cukup menarik. Ada sebuah persoalan bahwa di dalam teks Pengakuan Pariyem terdapat hegemoni kelas priyayi terhadap kaum rakyat biasa. Dari kacamata kelisanan, tokoh Pariyem bisa leluasa membangun interaksi, komunikasi, emosi, dan sebuah 
keterlibatan yang erat hanya kepada golongannya sendiri (Mas Paiman), tidak dengan keluarga Ndoro Kanjeng. Sebaliknya, dalam hal peneladanan, Pariyem tidak mendapatkannya dari sosok "Mas Paiman" yang sekelas dengannya, tetapi keteladanan yang ia tiru bersumber dari keluarga nDoro Kanjeng, suatu kelas yang bagi Pariyem penuh dengan idealisme kehidupan. Kedua hal tersebut menandakan bahwa dua gologan tersebut terpisah oleh sekat-sekat ideologis. Seerat apapun interaksi yang coba dibangun oleh keduanya akan tetap mengakibatkan kelas rakyat biasa tetap menjadi kelas yang lebih rendah dibandingkan dengan kaum bangsawan. Di dalam teks, persoalan itu tampak dengan kembalinya kehidupan Pariyem seperti semula, sebagai babu di keluarga nDoro Kanjeng, meskipun di satu sisi dirinya telah memberikan keturunan bagi majikannya. Pariyem sampai kapan pun tetap akan berstatus pembantu dan keluarga nDoro Kanjeng akan berstatus majikan bagi Pariyem.

\section{Daftar Pustaka}

Dananjaya, James. 1984. Folklor Indonesia: Ilmu Gosip, Dongeng, dan lain-lain. Jakarta: Grafitipers
Fang, Liauw Yock. 1991. Sejarah Kesusastraan Melayu Klasik. Jakarta: Erlangga.

Finnegan, Ruth. 1977. Oral Poetry: its Nature Significance and Social Context. London and New York: Cambridge University Press.

H.T., Faruk. 1994. Pengantar Sosiologi Sastra: dari Strukturalisme Genetik sampai Postmodernisme. Yogyakarta: Pustaka Pelajar.

Hutomo, Suripan Sadi. 1991. Mutiara yang Terlupakan. Surabaya, Jawa Timur: HISKI.

--------, 2000. Women-Womeni Lupus. Magelang: Indonesiatera.

Jan Van Luxemburg. dkk. 1989. Pengantar Ilmu Sastra. Diindonesiakan oleh Dick Hartoko. Jakarta: Gramedia Pustaka Utama.

MPSS, Pudentia (Ed). 2008. Metodologi Kajian Tradisi Lisan. Jakarta Timur: Asosiasi Tradisi Lisan.

Ong, Walter J. 1977. Interface of The Word. Ithaca: Cornel University Press.

2002. Orality and Literacy: The Technologizing of the Word. London and New York: Routledge.

Pradopo, Rachmat Djoko. 2003. Beberapa Teori Sastra, Metode Kritik, dan Penerapannya. Cetakan kedua. Yogyakarta: Pustaka Pelajar.

Subagio Sastrowardoyo dkk (Ed.) 1983. Anthology of ASEAN Literature: Oral Literature of Indonesia. Tanpa nama kota: The ASEAN comitte on Culture and Information. 
Mabasan, Vol. 8, No. 1, januari-Juni 2014: 14-33

Strinati, Dominic. 2009. Popular Culture: Pengantar Menuju Teori Budaya Populer. Yogyakarta: Arr Ruzz Media.

Suryadi, Ag. 2002. Pengakuan Pariyem: Dunia Batin Seorang Wanita Jawa. Cetakan keenam. Yogyakarta: Pustaka Pelajar.

Sweeney, Amin. 1980. Authors and Audience in Traditional Malay Literature. Berkeley, California: Center For South and Southeast Asia Studies; University of California.

Teeuw, A. 1991. Membaca dan Menilai Sastra. Jakarta: Gramedia Pustaka Utama.

------------, 1994. Indonesia antara Kelisanan dan Keberaksaraan. Jakarta: Pustaka Jaya. 